\title{
Pigmentary Glaucoma versus Angular Closure
}

\section{Vicmel ZG*, Mairelys CD and Juana Beatriz ZG}

First Degree Specialist in Ophthalmology and MGI, Cuba

*Corresponding author: Vicmel Zamora González, First Degree Specialist in Ophthalmology and MGI, MINSAP/UCMH, street 36 N. 1305 Artemisa Cuba, Cuba, Tel: +5352547015; Email: zvicmel@gmail.com

\section{Case Report}

Volume 4 Issue 2

Received Date: February 21, 2019

Published Date: March 27, 2019

DOI: $10.23880 /$ oajo-16000177

\section{Abstract}

Pigmentary Glaucoma is a bilateral process characterized by the deposit of pigment granules throughout the anterior segment that causes an increase in intraocular pressure due to pigmentary obstruction and injury to the trabeculum. We present a patient with a previous history of elevated intraocular pressure treated with timolol $0.5 \%$ that arrives to consultation with blurred vision. Ophthalmological examination revealed a compound hypermetropic astigmatism with elevated intraocular pressures, the presence of guttas in the endothelium and narrowing of the anterior chamber, deposits of endothelial pigments and in the lens also opacified and in the trabeculum, with angular closure. In the fundus of the eye, asymmetry was observed in the excavations and visual alterations appeared in the field. The IOL Master 700 corroborated that it is a patient with small eyes and narrow cameras, something that is not frequent in Pigmentary Glaucoma, for which an angular closure is also proposed.

Keywords: Pigmentary Glaucoma; Angular Closure

\section{Introduction}

Pigment dispersion syndrome (PPS) is a rare bilateral process characterized by the deposit of pigment granules throughout the anterior segment. Some patients with SDP develop an open angle glaucoma of trabecular blockade (pigmentary glaucoma). Affected individuals are, in general, male, white race, myopic between the second and fifth decades of life. SDP is caused by the dispersion of the pigment caused by mechanical contact between the posterior pigmented layer of the iris and the anterior surface of the zonule fibers, as a result of excessive posterior bulging of the peripheral portion of the iris [1-3]. The pigment granules are released in the aqueous humor and are deposited in all the structures of the anterior chamber, including the trabecular meshwork [4]. The elevation of intraocular pressure seems to be caused by pigmentary obstruction and trabecular injury, secondary to the release of pigment from the pigment epithelium of the iris that is phagocytosed by trabecular endothelial cells. When these cells are depleted by pigment overload, they undergo autolysis or migrate from the trabecular bundles, which would explain the chronic and fluctuating course of intraocular pressure. Intraocular pressure increases after pupillary dilation, accommodation and exercise $[5,6]$.

\section{Clinical Examination}

- Pigmentary deposits in the corneal endothelium (Krukenberg spindle), the iris and the periphery of the lens (Scheie band or Zentmeyer line).

- Radial transillumination defects in the iris.

- Concave peripheral iris. 
- Trabecular hyperpigmentation.

- Sometimes there may be particles of pigment floating in the anterior chamber and may be confused with active uveitis $[7,8]$.

\section{Presentation of the Case}

A 61-year-old female patient with a history of hypertension 10 years ago with stable and compensated medical treatment. She says that for the last 2 years she has been treated with Timolol $0.5 \%$ twice a day for glaucoma diagnosis, presenting high intraocular pressure (IOP) at the time of diagnosis: infinity in (OD) and $19 \mathrm{mmHg}$ in (OI), taken with the Shiotz tonometer.

General personal pathological history of arterial hypertension and eye symptoms of chronic simple glaucoma.

General family pathological history of hypertension by her mother and glaucoma eyeglasses by her uncle through the mother.

At the ophthalmological physical examination we find:

Visual acuity (AV): Right eye (RE) 0.1 and Left eye (LE) 0.3

Dynamic Refraction (DR): (RE): + 3.00-0.50x160 (AV: 0.6 nmae)

(LE): + 3.50-0.75x175 (AV: 0.8 nmae)

ADD: +3.00 esf / J2

Intraocular pressure (IOP) taken with the Goldman applanation tonometer: (RE): $19.0 \mathrm{mmHg}$ and (LE): $18.0 \mathrm{mmHg}$.

Annexes: No alterations to both eyes.

Previous Segment: Presence of endothelial guttas, the anterior chamber impresses narrow Grade-II by VanHerrick. Use of Krukemberg both eyes.

Refractive Media: Partial opacity of both crystals.

\section{Fundus Oculi}

RE: Excavation 0.6 of superior vertical elongation with nasal rejection of the vessels; vessels in bayonet in upper sector; narrowing of the neuroretinal ring in superior temporal. Decreased arterial caliber with increased arterial brightness. Macula and retina without alterations. LE: 0.2 central excavation with preserved neuroretinal ring. Decreased arterial caliber with increased arterial brightness. Macula and retina without alterations.

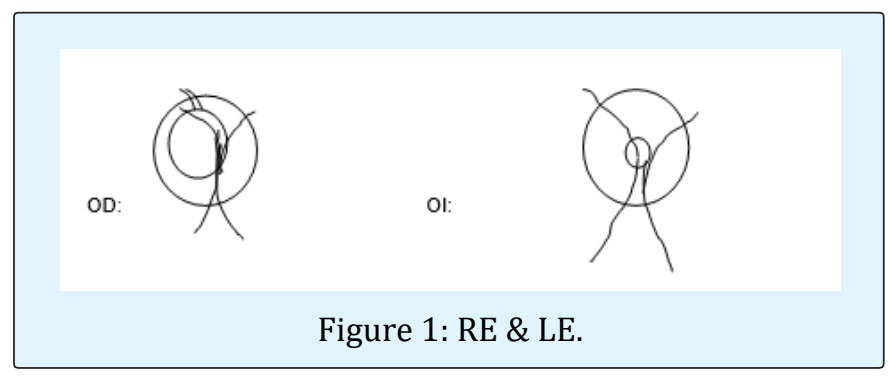

Pupillary Reflections: Preserved in both eyes. Primary look position: Orthophoria both eyes. Eye movements: No limitations.

Gonioscopy in the primary position of the gaze: A nonpigmented trabeculum is observed with pigment dispersion and a pigmented schwalbe line. Iris domed in periphery in both eyes.

Gonioscopy in the extreme position of the gaze: Very pigmented trabecular mesh $\times \times \times \times$. Spur by sectors.

Note: History collected from the PIO before arriving at the current consultation.

\begin{tabular}{|c|c|c|}
\hline $\mathbf{R E}$ & $\mathbf{L E}$ & \\
\hline$\infty$ & $19.0 \mathrm{mmHg}$ & without treatment \\
\hline $\begin{array}{l}19.0 \mathrm{mmHg} \\
(27 \mathrm{mmHg})\end{array}$ & $24.0 \mathrm{mmHg}(32 \mathrm{mmHG})$ & with treatment \\
\hline $\begin{array}{l}10.0 \mathrm{mmHg} \\
(18 \mathrm{mmHg})\end{array}$ & $16.0 \mathrm{mmHg}(25 \mathrm{mmHg})$ & with treatment \\
\hline $\begin{array}{l}21.0 \mathrm{mmHg} \\
(29 \mathrm{mmHg})\end{array}$ & $11.0 \mathrm{mmHg}(20 \mathrm{mmHg})$ & with treatment \\
\hline
\end{tabular}

Table 1: RE \& LE.

Diagnostic impression: -Catarata both eyes

- Pigmentary Glaucoma

Studies to determine definitive diagnosis are indicated: Pachymetry, HRT, computerized Campimetry, anterior segment photograph, anterior segment OCT, IOL master, endothelial microscopy.

Pachymetry: RE: 462 LE: 449

OCT of anterior segment:

- RE: narrow angle of $19^{\circ}$.

- LE: open angle of $31^{\circ}$.

\begin{tabular}{|c|c|c|}
\hline & RE & LE \\
\hline CD & 2380 & 2481 \\
\hline CV & 34 & 47 \\
\hline Hexag & 63 & 50 \\
\hline P & 475 & 447 \\
\hline
\end{tabular}

Table 2: Endothelial Microscopy. 
Disruption of the endothelial mosaic. Pleomorphism and Polymegatism. Presence of endothelial guttas

\begin{tabular}{|c|c|c|}
\hline & $\mathbf{R E}$ & $\mathbf{L E}$ \\
\hline \multirow{2}{*}{$\mathrm{K}$} & 44.76 & 44.64 \\
\cline { 2 - 3 } & 44.00 & 43.95 \\
\hline $\mathrm{LA}$ & 21.82 & 21.93 \\
\hline $\mathrm{AC}$ & 2.33 & 2.78 \\
\hline \multirow{2}{*}{ LOI (SRK-T) } & $25.0(-0.14)$ & $25.0(-0.35)$ \\
\cline { 2 - 3 } & $24.0(0.58)$ & $24.0(0.37)$ \\
\hline
\end{tabular}

\begin{tabular}{|c|c|c|}
\hline & $\mathbf{R E}$ & $\mathbf{L E}$ \\
& $\mathbf{2 1 . 7 2}$ & $\mathbf{2 1 . 8 8}$ \\
\hline \multirow{2}{*}{$\mathrm{K}$} & $44.57^{*} 100$ & $44.40 * 90$ \\
\cline { 2 - 3 } & $42.89 * 10$ & $43.84 * 180$ \\
\hline CA & 225 & 265 \\
\hline LT & 534 & 519 \\
\hline CCT & 465 & 446 \\
\hline WTW & 11.8 & 12.5 \\
\hline
\end{tabular}

Table 4: IOL-Master 700.

Table 3: IOL- Master.

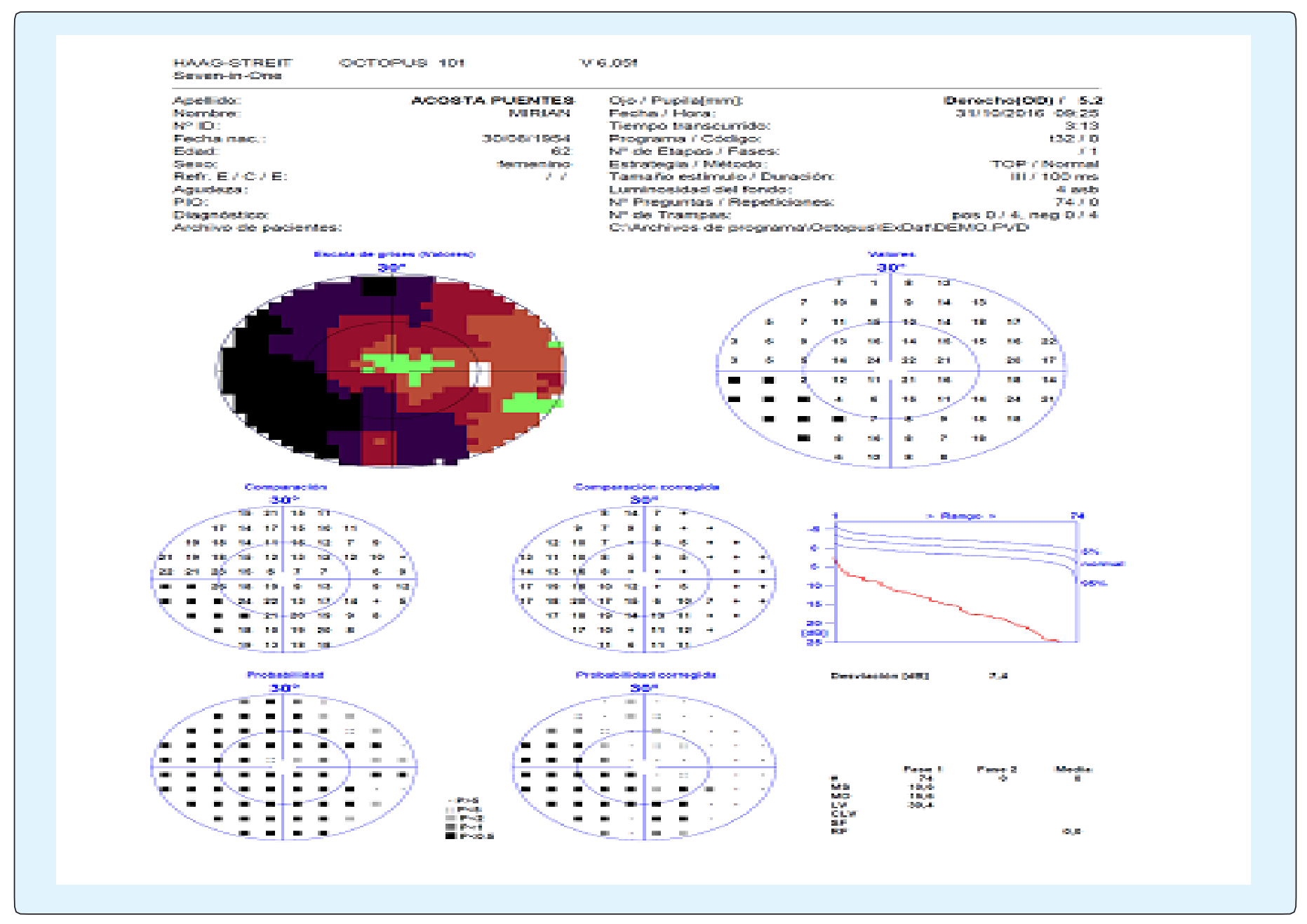




\section{Open Access Journal of Ophthalmology}

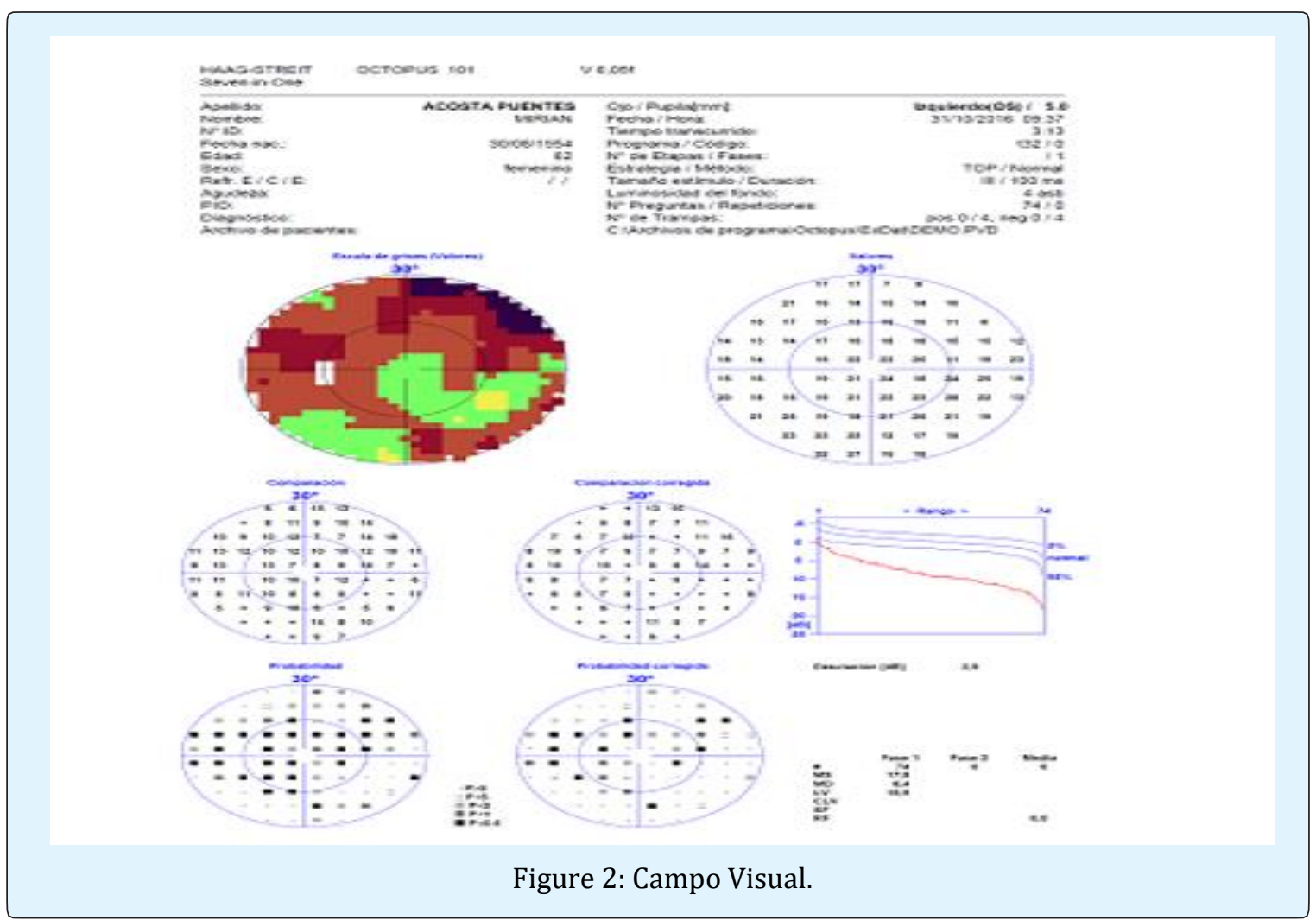

\section{Discussion}

In the results we found that the patient presented central corneal thickness (CCT) below 505, which is a high risk factor in glaucoma $[9,10]$. This shows that his corneas are thin which underestimates the IOP value so if he presented in the consultation values of: $19.0 \mathrm{mmHg}$ and $18.0 \mathrm{mmHg}$ with Timolol $0.5 \%$ twice a day, correcting it according to pachymetry would be $21.0 \mathrm{mmHg}$ in eye right and left eye $20.0 \mathrm{mmHg}$ and taking into account the asymmetry of the excavations and disc appearance over the entire right eye and the previous history of intraocular pressure values, it was decided to incorporate the treatment Latanoprost $0.005 \% 1$ drop at 9:00 p.m. It was also found that the patient presented Endothelial Dystrophy of Fuch by endothelial microscopy and was corroborated with the IOL Master which is a patient with small eyes and narrow chambers, something that is not frequent in pigmentary Glaucoma, these patients being characterized more by present open angles and more frequently in myopic patients [1,2,4,11]. Assess the possibility that they are large crystals and is the cause of the angular narrowing which is corrected with extracapsular lens extraction and implant of the intraocular lens and lens sac. You must take into account the characteristics of your corneas to choose the most appropriate surgical technique, thus avoiding a corneal decompensation with the consequent bullous keratopathy that can result [12]. This is a sample that must be careful when examining a patient and perform all exams that are deemed necessary to preserve the visual health of it and that the final result is successful.

\section{References}

1. Lascaratos G, Shah A, Garway Heath DF (2013) The genetics of pigment dispersion syndrome and pigmentary glaucoma. Surv Ophthalmol 58(2): 164175.

2. SooHoo J, Seibold L, Kahook M (2013) Recent advances in the management of Neovascular glaucoma. Seminars In Ophthalmology 28 (3): 165172.

3. Kuchtey J, Chen Chang T, Panagis L, Kuchtey RW (2013) Marfan syndrome produced by a novel FBN1 mutation with associated pigmentary glaucoma. Am J Med Genet A 161A(4): 880-883. 


\section{Open Access Journal of Ophthalmology}

4. Hong Y, Sun YX, Qi H, Zhou JC, Hao YS (2013) Pigment dispersion glaucoma induced by the chaing effect of intraocular lens haptics in Asian eyes. Curr Eye Res 38(3): 358-362.

5. Sivaraman KR, Patel CG, Vajaranant TS, Aref AA (2013) Secondary pigmentary glaucoma in patients with underlying primary pigment dispersion syndrome. Clin Ophthalmol 7: 561-566.

6. Burgos R, Pongo V, Parra J, Rueda J (2007) Pigmentary glaucoma. (Spanish) Medunab 10(2): 106-109.

7. Farrar SM, Shields MB, Miller KN, Stoup CM (2010) Risk factors for the development and severity of glaucoma in the pigment dispersion syndrome. Am J Ophthalmol 108(3): 223-229.

8. Flügel Koch CM, Tektas OY, Kaufman PL, Paulsen FP, Lütjen Drecoll E (2014) Morphological alterations within the fixation of the iris dilator muscle in eyes with pigmentary glaucoma. Investigative Ophthalmology \& Visual Science 55(7): 4541-4551.

9. Carasssa R (1997) Laser Iridotomy in pigmentary glaucoma 5 .

10. Peyret A Mastery pigmentary and pseudoexfoliative glaucoma

11. Dada T, Gadia R, Sharma A, Ichhpujani P, Bali S, et al. (2011) Ultrasound biomicroscopy in glaucoma. Survey of Ophthalmology 56(5): 433-450.

12. Rosentreter A, Schwenn O, Funk J, Dietlein T (2013) Der Ophthalmologe: Zeitschrift Der Deutschen Ophthalmologischen Gesellschaft 110(4): 306-309. 